\title{
Self-injurious behaviors among adolescents. A qualitative study of characteristics, meanings, and contexts
}

\author{
Gonzalo Agüero, M.D., ${ }^{a}$ Viviana Medina, M.D., ${ }^{a}$ Gabriel Obradovich, M.D., ${ }^{b}$ \\ and Enrique Berner, M.D. ${ }^{a}$
}

\begin{abstract}
Introduction. Self-injurious behaviors, such as cutting, are quickly spread and transmitted among adolescents, although it is not clear how. Our objective was to describe and analyze the social interactions occurring in relation to these behaviors.

Populationandmethods. Descriptive, qualitative, and cross-sectional design. Population: adolescents with self-injuries detected at the Department of Adolescence between June 2015 and May 2016. Sampling was purposive and randomized until reaching information redundancy. Data were collected from audio-recorded, semi-structured interviews. Descriptive categories were developed based on personal relationships regarding self-injuries. Results. Thirty-six adolescents were included (33 girls). Age: $15.2 \pm 1.9$ years. Self-injuries occurred in contexts of conflict with the adult world due to tensions in the household and a neglect of the problems affecting adolescents. Skin cutting was done alone, hidden from the family but shared with peers. Among adolescents, cuts functioned as symbols for their suffering and generated strong ties of identification, belonging, and empathy. Wounds became a recognized and shared asset, around which they grouped their discourse, affection, and other representations of the moment they were living.

Conclusions. Self-injuries provide a transient emotional relief; they are usually in opposition to the adult world, and strong ties of belonging and identification are developed among peers in relation to such injuries. This configuration favors concealment of such behavior from the family and its circulation among adolescents.

Key words: Self-harming behavior, adolescent, puberty, girls.
\end{abstract}

http: / / dx.doi.org/10.5546/ aap.2018.eng.394

Gonzalo Agüero, M.D.: aguerogonzalo@gmail. com

Funding:

Research fellowship granted by the Sociedad Argentina de Pediatría (2015).

Conflict of interest:
None.

Received: 1-11-2018

Accepted: 5-17-2018
To cite: Agüero G, Medina V, Obradovich G, Berner E. qualitative study of characteristics, meanings, and contexts. Arch Argent Pediatr 2018;116(6):394-401.

\section{INTRODUCTION}

Self-injuries are deliberate actions aimed at harming oneself by mutilating body tissues, such as cutting or burning. Individuals who do this seek to relieve negative emotions or solve an interpersonal conflict. $^{1}$

This is typically observed in girls during their early adolescence. The most common method is that of cutting, ${ }^{2,3}$ whose prevalence is $16-18 \%$ at an international level. ${ }^{4}$ Self-injurious behaviors are a risk factor associated with mental disease and suicide attempts. ${ }^{5,6}$ The Child \& Adolescent Self-harm in Europe (CASE) Study showed that these adolescents made up a high-risk "hidden" population who, in general, did not seek medical care, went unnoticed by their families, and usually seriously considered harming themselves or taking a drug overdose. ${ }^{7}$

These behaviors are frequently spread and transmitted among adolescents, although it is not clear how. ${ }^{5}$ It is believed that social networks play a key role. ${ }^{8}$ Some authors have pointed out that the purpose of self-injuries is to seek help and draw attention from other people; ${ }^{9,10}$ however, the analysis of how such process takes place is limited. Our objective was to do a qualitative analysis of the meanings, processes, and contexts of selfinjuring adolescents. Particularly, how adolescents started, the meaning assigned by them to such injuries, the circumstances in which they did it, and how the people in their environment reacted. 


\section{POPULATION, MATERIALS AND METHODS}

Design: Descriptive, qualitative, and crosssectional

Population: Adolescents seen between June $1^{\text {st }}, 2015$ and May 31 ${ }^{\text {st }}, 2016$ at the Department of Adolescence of Hospital Argerich, where clinical and gynecological-obstetric care was provided. The study protocol was approved by the hospital's Research Ethics Committee. An informed consent was obtained from adolescents $\geq 14$ years old and from the adult caregivers of those younger than 14 years. The necessary measures were taken to ensure participants' anonymity. If necessary, participants were referred to the Department of Mental Health.

Inclusion criteria: Outpatients aged 12-
20 years with deliberate self-injuries detected either during an interview or physical examination, regardless of the reason for consultation.

Exclusion criteria: Risky behaviors without deliberate self-injurious attempt (tattoos, piercings, non-compliance with traffic regulations, unprotected sexual intercourse), selfinjury disorders (mental retardation, autism), an uncontrolled psychiatric condition, refusal to participate in the study.

Instrument: An exploratory questionnaire with open-ended questions was developed based on the bibliography, especially the CASE Study ${ }^{7}$ (Table 1). The same health care provider conducted a semi-structured interview with each participant in a private setting, which

TABLE 1. Domains, definitions, and indicators used to explore self-injurious behaviors among adolescents

\section{Domain}

Self-injurious behaviors

(definition from the

CASE Study, 2008) ${ }^{7}$

\section{Definition}

Deliberate, present or past behaviors without fatal outcome with the intention of causing bodily damage.
Most recent event

Description of the self-injurious event

Function or incentive

Premeditation

Medical care requirement

Stressful life events

Adult role model

Significant people with self-injuries

Social networks*

The role of music**
It was classified into recent ( $<3$ months ago) or old ( $\geq 3$ months ago).

Description of the most remembered event and associated situations. Among those who did it only once, the single event was described.

Description of reason or incentive that triggered or promoted the self-injurious event.

An attempt to define whether the self-injurious behavior had been planned or impulsive.

Assessment of the requirement of medical care.after a self-injury.

Life events related to the initiation and/or persistence of self-injuries.

Presence and role of trusted adults (mother, father or other adult role model) in the self-injury process.

People with whom they shared a routine or had an emotional bond.

Use of social networks

(Facebook, Instagram, Twitter, blogs, forums, etc.) in relation to self-injuries.

Favorite music and its influence on the initiation, repetition or discontinuation of self-injurious behaviors.

\section{Indicators}

The participant deliberately did one or more of the following: self-injurious behavior (cutting, burning, hitting, etc.), drug intake at a dose higher than that prescribed or generally recognized as therapeutic, recreational or illegal drug use aimed at harming him/herself.

Time elapsed since the most recent event.

Place and method(s) used, presence of other people, emotional situation before and/or after the event, influence of alcohol and/or drugs, asking for help before and/or after the event.

Implicit or explicit reasons or incentives associated with the personal and/or relationship context.

Assessment of the context and time elapsed between having the idea of self-harm and doing it.

Visiting the Emergency Department

Stressful life events in the past 12 months.

Relationship with the family and presence of trusted adults: interaction in relation to self-injuries.

Self-injuries in a group, within the family or school environment, with friends and/or a partner.

Participation in groups with information on self-injuries; seeing and sharing related pictures and/or phrases; publishing pictures of their own injuries.

Favorite music (style, band, singer);

influence of music on self-injurious behavior.

\footnotetext{
* These domains were introduced after the first two interviews due to the relevance assigned to them during participants' accounts. ${ }^{* *}$ Music plays a key role in psychosocial and personal development and in the establishment of friendships during adolescence; depending on circumstances, it may work as a protective or risk factor.
} 
was audio-recorded. The following data were collected for population categorization purposes: age, sex, level of education, nationality, sexual development (according to Lejarraga), ${ }^{11}$ and level of education of the adult caregiver.

Recruitment: Purposive, randomized sampling. During the medical visit, participants were asked: "Have you ever harmed yourself on purpose because you felt bad?" Besides, during the physical examination, their body was examined for typical scars. Patients who were detected were sequentially included until meeting the "redundancy" principle. ${ }^{12}$

Adolescents standing with a pronated forearm (Annex 1): It consists in actively keeping the injured arm in a pronated position while the other arm is in a natural position. This position is used to conceal scars in the forearm. Variants of this position may be observed depending on whether the adolescent is sitting down or moving around the physician's office.

Analysis: Audio-recordings were transcribed and interviews were read and compared according to the domains described here (Table 1). Discourse was analyzed in three levels: textual, contextual, and social, to establish descriptive categories of the set of relationships around the self-injuring action.

\section{RESULTS}

Thirty-six adolescents were interviewed; their average age was $15.2 \pm 1.9$ years (median: 15 ).
An in-depth analysis was done for 29 interviews (Figure 1 and Table 2); 6 interviews were too brief. Discourse theoretical saturation was achieved (Annexes 2 and 3). Quotes correspond to verbatim words or phrases from the interviews.

Initiation: The age at initiation was $12.9 \pm 1.3$ years (range: $10-16$; median: 13 ); in average, 1 to 2 years after the menarche (menarche: $11.4 \pm 1.3$ years; median: 11 years). The time elapsed until such behaviors evolved was 20 months (range: 6-72; median: 12). At the time of the study, 21 adolescents had stopped doing it; 17 were referred to the Department of Mental Health and 7 were receiving treatment or had completed it. Although one third of participants started with a self-injurious behavior while in primary school, in all cases, it occurred at an advanced pubertal stage. Cutting was the most common method. Based on their accounts, significant people appeared in their lives who had or had had self-injuries, mostly school mates, friends, siblings or partners. Becoming aware of these stories legitimized self-injuries as a potential outlet to "express pain" or "feel better." In turn, interviewees acted as models for other adolescents to start this behavior.

Context: Cuts were related to a situation of sorrow and emotional distress. As an expression, cuts revealed sorrow and distress. Most interviewees admitted that stressful life events had promoted the initiation or persistence of self-

FIGURE 1. Flowchart of study participants

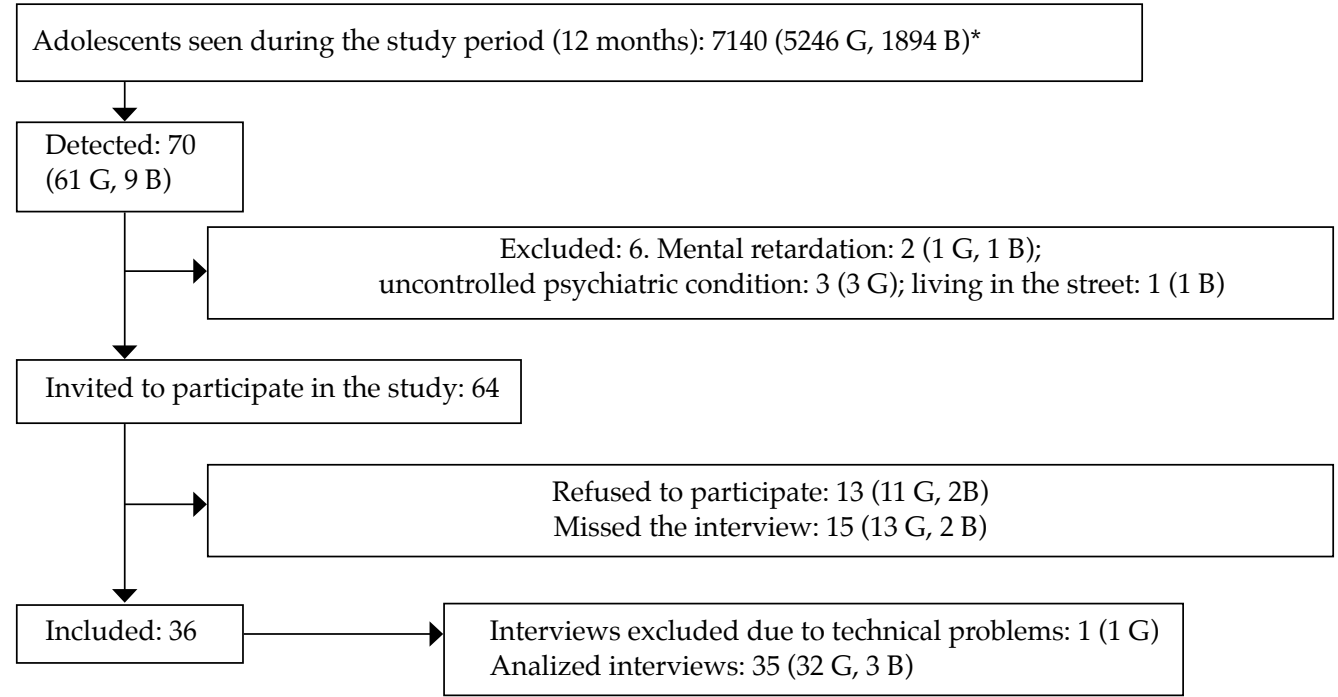

G: girl; B: Boy. 
FIGURE 2. Stressful life events in 36 adolescents with self-injurious behaviors

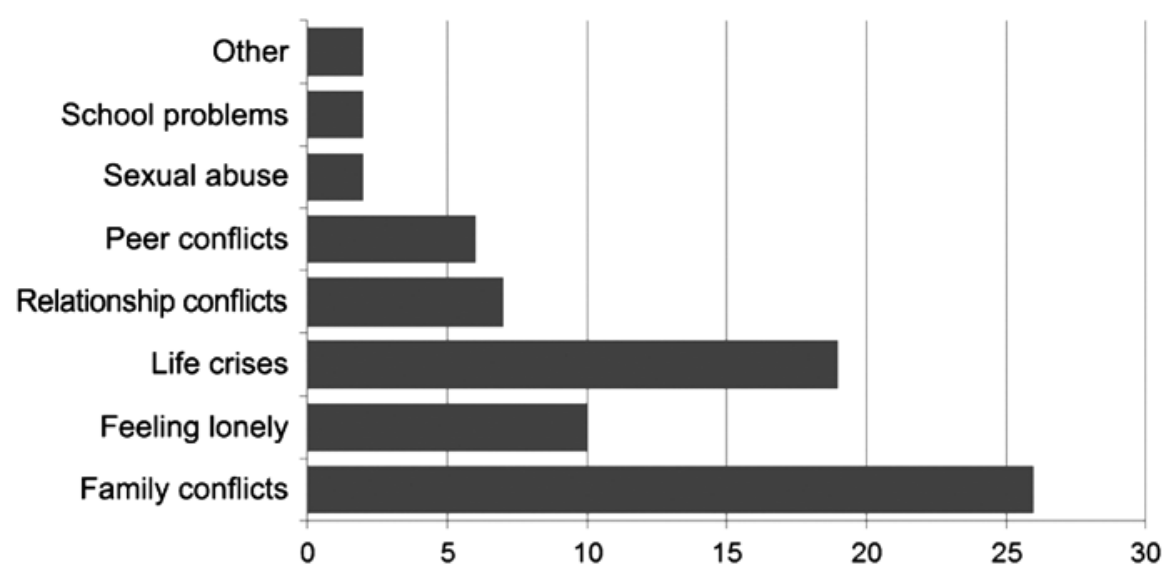

Life crises referred to a disease in or the death of a family member, changing schools or moving.

TABLE 2. Population data of 36 adolescents with self-injurious behaviors

\section{Outcome measures}

Occupation

Over-aged student

Place of origin

Nationality

Maximum level of education completed by adult caregiver

Type of self-injurious event

Method

Situation or "scene"

for self-injury

Care at the

Emergency Department

Continues with self-injuries

Uses social networks

in relation to self-injuries

Significant people who have or had self-injurious behaviors
Study

Study and work

Neither study nor work

No

Yes

CABA

GBA

Argentine

Other

Complete primary education

Incomplete/complete secondary education

Incomplete/complete tertiary/university education

Frequency $(\%)$

Single (no reoccurrence)

Repeated in an isolated manner (weekly, monthly) 23

$\begin{array}{ll}\text { Repeated in a persistent manner (daily) } & 7\end{array}$

$\begin{array}{ll}\text { Single (mostly cutting) } & 19\end{array}$

Multiple (cutting + pill intake \pm other) 17

Alone (at home) 25

With others (at home, at school) 3

Both (at home, at school)

No 32

Yes 4

$\begin{array}{lr}\text { No } & 21\end{array}$

Yes $\quad 15$

Participates in groups (Facebook, forums, blogs) on this topic 15

Sees and shares pictures or related phrases (Facebook, Instagram, blogs) 8

Does not use them to this end 13

None

1 person 18

More than 1 person 13

CABA: Autonomous City of Buenos Aires; GBA: Greater Buenos Aires Area. 
injuries (Figure 2).

Typically, these were done at home, during the night; they were a private, secret action. Their prior emotional status was intense and negative (sadness, anger, loneliness, hopelessness) and exceeded their coping skills. Cuts acted as an "escape route" and provided a temporary feeling of comfort ("freedom," "discharge," "outlet," "relief," "a weight off my shoulders"). Physical pain helped them to "forget" about their emotional or psychological suffering, to "trade one type of pain for another." Thus, emotional regulation was the most frequent incentive to do it (Figure 3). After doing it, they cleaned their wounds and, at home, pretended "nothing had happened." Exceptionally, they sought medical care for their wounds. Self-injuries tended to be repeated when faced with new conflicts.

In some adolescents, self-injuries became cyclic, triggered by subjective conflicts, such as "doing something wrong," "guilt," "failure to fulfill goals." Cutting was usually "addictive" and out of control. Participants described depressive symptoms, anxiety, low self-esteem, dissatisfaction with body image, and trouble solving interpersonal problems.

Occasionally, self-injuries occurred in group settings, and varied from rites of passage or peer identification (group self-injury) to a search for help and attention, or in situations considered unfair (self-injury in front of others).

Premeditation: Each event was repeated as a stereotype, in a context of overwhelming feelings and in response to a stressful event. Cutting is an impulsive action, done "without thinking."
Adolescents with repeated self-injuries frequently showed simultaneous impulsive events and planned or anticipatory behaviors.

- Supplies: stacking sharp objects, which are kept hidden for future self-injurious events.

- Camouflage: strategies aimed at concealing wounds, including the type of clothes, a change in family physical contact and physical habits, such as the pronated forearm position in adolescents.

- Wound care: wounds were regularly cleaned and "healed" with an antiseptic solution and/ or a healing ointment. No infected self-injuries were observed.

- Assessment of risk from self-injuries: there were precautions taken to avoid harming "vital" structures; these were mostly beliefs transmitted among adolescents. Forearm "veins" were considered a "vital" place; knowing how close or far from a "vein" the wound was indicated the risk of death to which they had been exposed.

Adult world: During interviews, participants reported that they had no trusted adults with whom to talk about their problems. They pointed out that adults were involved in their own problems and did not pay enough attention to them. They highlighted a lack of genuine concern and display of affection, and considered that the family reaction to the situation was inadequate.

"Suicides": Cutting created a strong identification and empathy bond, which differentiated them ("us," "the ones who cut themselves") from "them," "the normal ones." "Suicides" had a special sensitivity, understood one another, "understood their reasons, the pain, and the scars." According to them, they had valid

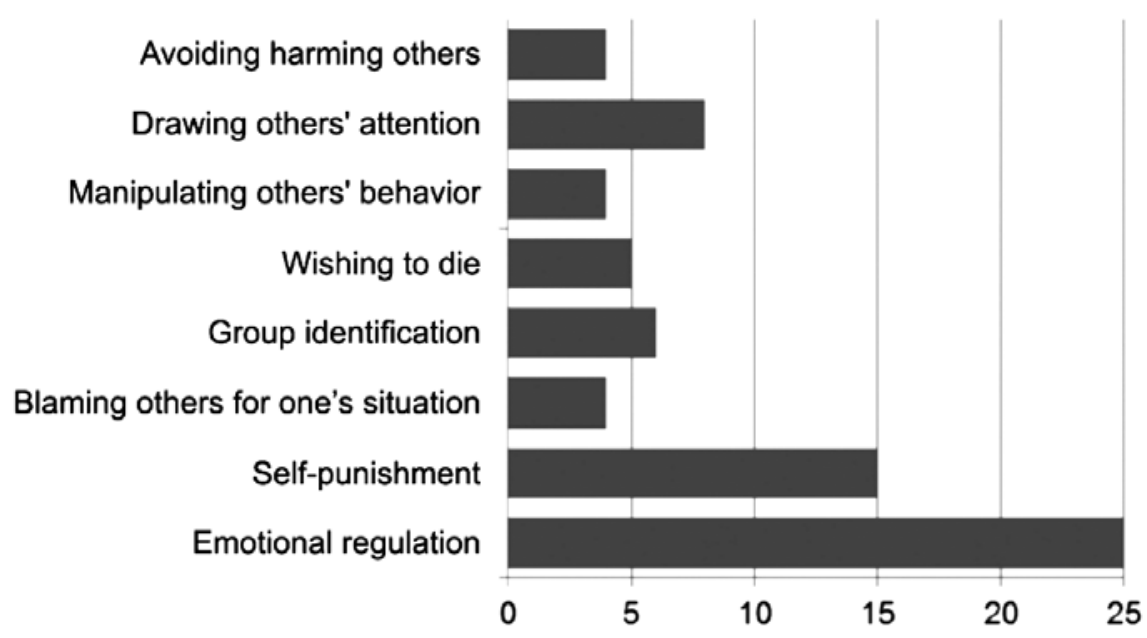


reasons to do it ("family problems," "love," "an outlet," "looking for help") and objectionable reasons ("fashion," "because others did it," and "to draw attention"). They also showed great ambiguity in relation to death and did not want others to harm themselves; for this reason, they usually listened to one another, gave advice, and accompanied others in person or through social networks.

It is striking that adolescents at a high risk for suicide (highly lethal methods, high level of planning, psychiatric comorbidity or attempted suicide) did not called themselves "suicides."

Social networks: Many interviewed girls used social networks to publish pictures or participate in groups about self-injuries, and to share, find comfort, and ask for help. There they could redefine their cuts, talk about them naturally, and feel visible and observed. However, other adolescents negatively assessed the use of social networks to this end because they felt they were only used "to draw attention" or because it was a "fashion."

\section{DISCUSSION}

The findings from the interviews were consistent with the bibliography: the most common reason for self-injury is seeking relief or emotional regulation; ${ }^{10}$ self-injuries start in adolescents during advanced puberty; ${ }^{13}$ the most commonly used method was cutting; ${ }^{3,7,14}$ there is little premeditation; ${ }^{7}$ self-injuries are usually concurrent with emotional problems (low selfesteem, difficulty solving interpersonal conflicts, impulsivity, and symptoms of anxiety and depression); ${ }^{15}$ the transmission of self-injuries is common among peers, ${ }^{5,9}$ and, lastly, social networks play an important role in this process. ${ }^{8}$

Self-injuries are promoted by highly variable situations; however, our study showed that they were mostly related to family conflicts. Adolescents have a troubled relationship with the adult world, especially with their parents. They feel their suffering is neglected and that they are invisible. They report that adults consider that teenage dating problems are not serious compared to family dramas, that school and friendship conflicts are minimal compared to work-related problems. As pointed out, ${ }^{16}$ adults reflect an image that denotes that adolescents' problems are minor or little serious. Probably due to such antagonism, the ritual of cutting and its symbols are organized in opposition to the adult world. This is significant to understand the difficulties that families have to detect this type of behaviors. For this reason, adolescents conceal and camouflage their wounds, but when they go unnoticed by their family, they become the victims of a double invisibilization.

An aspect of self-injuries that has not been fully addressed is that of their social domain. ${ }^{79,15-18}$ Cuts are usually described as individual actions, detached from any social relation; possibly because most are done privately and their main function is that of emotional relief. ${ }^{10,17,19,20}$ This perspective assumes that the problem of selfinjuries lie in the adolescent and not in his/her relationship system and environment. However, our study shows a piece of information that contradicts the foregoing: no infections were recorded in relation to self-injuries. This is because adolescents conduct the self-injury ritual, and the care of their wounds, with great affection, so they clean, cover, and heal them with antiseptic solutions and/or healing ointment. Cuts and scars are their symbols of personal sorrow and distress; having them means "feeling bad," "suffering," and/or "having problems." This is evident with the circulation of cuts among peers: they interact based on their wounds. They gain visibility when talking about their wounds, telling their problems, and expressing disapproval of the adult world. They exchange pictures and talk using social networks, such as Facebook, Instagram, blogs, and WhatsApp groups. Cuts, their depth, the problems that trigger cutting, and the resulting discomfort become a shared asset among peers, one that grants them recognition, respect, and help.

The relationship system during adolescence is strongly influenced by the peer subculture, where there is a strong, influential interaction based on common interests. These interactions are key in the development of identity and autonomy..$^{21,22}$ Actually, interpersonal relations established around cutting take place within such logic of identity and autonomy development. On the one side, the adult world is excluded and disapproved of because adolescents feel invisible; on the other side, they differentiate themselves from "normal" adolescents, who cannot understand their suffering. In the group of "self-injuring" or "suicidal" adolescents, they exchange recognition and respect of suffering, thus creating strong bonds of belonging and identification. However, they jealously differentiate from other adolescents who also harm themselves but for objectionable reasons, "a fashion" or "to show off." They have mixed feelings in relation to their problems or 
seeking help, death, and their ability to harm themselves. They tend to look after their peers so that they will not continue harming themselves. Interpersonal conflicts, ambiguity, and looking for authenticity were also described as findings by Crouch and Wright in adolescents hospitalized for self-injuries. ${ }^{17}$

Social networks allow users to create an online identity, publish content, and organize communities based on common interests. ${ }^{8,23,24}$ "Posting" pictures and stories of self-injuries seems to amplify the possibility of getting help and recognition from other people. Although many interviewed girls highlighted this as a positive thing, in some cases it may function as a reinforcement that favors the worsening of this type of behavior.

Given the large prevalence of adolescents with minor injuries ${ }^{3}$ and that self-injuries tend to reduce with time, even without intervention, ${ }^{2}$ some authors have considered that self-injuries act as a regulatory behavior during adolescence. ${ }^{3}$ In this regard, it has been hypothesized that the spread and transmission of self-injuries among some groups of adolescents are facilitated by the structuring role of these behaviors on the development of identity and autonomy, which are a key part of adolescent psychosocial development. Wounds become a shared asset among peers, around which they group their discourse, affections, and other representations of the moment they are living. In other words, self-injuries are disruptive behaviors framed within the normal adolescent development. Here, their purpose (seeking emotional relief or trying to solve an interpersonal conflict $)^{1}$ is acceptable, but the means to get to it is disruptive. However, we also agree with Selby et al., ${ }^{25}$ who draw the attention to the fact that such harmful behaviors should not be played down due to their maintenance over time, especially among girls, and their associated comorbidities.

Implications for clinical practice: Previous qualitative studies focused on patients who had been treated or hospitalized at the Department of Mental Health. Our study was conducted in outpatients seen at the Department of Adolescence. Family conflicts and neglect of problems affecting adolescents have a strong influence on the initiation or persistence of selfinjurious behaviors. Such disruptive behaviors are developed as opposed to, or as a complaint of, the adult world. It would be important to carry out larger studies, especially in the school setting, to assess the impact on Argentine adolescents.

Limitations: First of all, the hospital sample was not representative of the general population. In clinical settings, cutting was overrepresented, which may magnify one self-injurious profile over others. Anyway, these were outpatients seen at the Department of Adolescence, not those hospitalized in the Mental Health Unit. Second of all, the information was provided directly by adolescents; here, the emotional context may have influenced participants' accounts. And third of all, although the relationship structure and the meaning assigned to cuts seemed sort of consistent, the study's cross-sectional nature did not allow us to establish if characteristics observed here remained over time.

\section{CONCLUSIONS}

Adolescents with self-injurious behaviors have negative and intense feelings that are mostly triggered by family conflicts. Self-harm is a temporary, subjective resolution to these feelings and conflicts. Although cuts are mostly done alone, the behavior is then shared with their peers, thus creating a strong bond of identification and belonging. Cuts function as a symbol of personal distress; they are organized in opposition to the adult world and provide recognition and respect from their peers. Such dynamic favors concealment of self-injuries from the family and its transmission among adolescents.

\section{Acknowledgments}

We would like to thank Laura Belli, M.D., for her critical reading of the manuscript. Also, to Pablo Salgado, B.S., Carolina Corino, B.S., and Paula Raimondi, M.D., for their feedback during the study conduct.

\section{REFERENCES}

1. International Society for the Study of Self Injury (ISSS). Self injury. Fast facts about non suicidal self-injury. [Accessed on: December $4^{\text {th }}$, 2017]. Available at: http:/ / itriples.org / redesadmin $15 /$ fast-facts $/$.

2. Moran P, Coffey C, Romaniuk H, et al. The natural history of self-harm from adolescence to young adulthood: a population-based cohort study. Lancet 2012; 379(9812): 236-43.

3. Bresin K, Schoenleber M. Gender differences in the prevalence of nonsuicidal self-injury: A meta-analysis. ClinPsychol Rev 2015; 38:55-64.

4. Muehlenkamp JJ, Claes L, Havertape L, et al. International prevalence of adolescent non-suicidal self-injury and deliberate self-harm. Child Adolesc Psychiatry Ment Health 2012; 6:10.

5. Hawton K, Saunders K, O’Connor R. Self-harm and suicide in adolescents. Lancet 2012; 379(9837):2373-82. 
6. National Institute of Health and Care Excellence (NICE). Selfh-harm (QS34). NICE Quality Standard. 2013. [Accessed on: December $\left.4^{\text {th }}, 2017\right]$. Available at: https: / / www.nice.org.uk/guidance/ qs34/ resources / selfharmpdf-2098606243525.

7. Madge N, Hewitt A, Hawton K, et al. Deliberate selfharm within an international community sample of young people: comparative findings from the Child \& Adolescent Self-harm in Europe(CASE)Study.JChild Psychol Psychiatry 2008; 49(6):667-77.

8. Lewis S, Heath N, Michal N, et al. Non-suicidal self-injury, youth, and theinternet: whatmentalhealth professionalsneed to know. Child Adolesc Psychiatry Ment Health 2012; 6(1):13.

9. NocKM. Why do peoplehurt themselves? new insights into the nature and functions of self-injury. CurrDirPsycholsci 2009; 18(2):78-83.

10. Klonsky ED. The functions of deliberate self-injury: A review of the evidence. ClinPsychol Rev 2007; 27(2):226-39.

11. Lejarraga $\mathrm{H}$, Berner E, del Pino $M$, et al. Método no invasivo para la evaluación del desarrollo sexual en la adolescencia. Arch Argent Pediatr 2009; 107(5):423-9.

12. Pedraz Marcos A, Zarco Colón J, Ramasco Gutiérrez, et al eds. Conceptos claves en investigación cualitativa. Criterios de calidad y aspectos éticos. In: Pedraz Marcos A, Zarco Colón J, Ramasco Gutiérrez, et al eds. Investigación cualitativa. Barcelona, España: Elsevier 2014.Pages 11-27.

13. Patton G, Hemphill S, Beyers J, et al. Pubertal stage and deliberate self-harm in adolescents.J Am Acad Child Adolesc Psychiatry. 2007;46(4):508-14.

14. Agüero G, Arrate M, Berner E. Adolescentes con autoagresiones: serie de casos clínicos. IntraMed J 2017; 6(2):1-8.

15. Madge N, Hawton K, McMahon E, et al. Psychological characteristics, stressful life events and deliberate self- harm: findings from the Child \& Adolescent Self-harm in Europe (CASE) Study. Eur Child Adolesc Psychiatry 2011; 20(10):499-508

16. Sinclair J, Green J. Understanding resolution of deliberate self harm: qualitative interview study of patients' experiences. BMJ 2005; 330(7500):1112.

17. Crouch W, Wright J. Deliberate self-harm at an adolescent unit: a qualitative investigation. Clin Child PsycholPsychiat 2004; 9(2):185-204.

18. Barnes M, Gunnell D, Davies R, et al. Understanding vulnerability to self-harm in times of economic hardship and austerity: a qualitative study. BMJ Open 2016; 6(2):e010131.

19. Valencia C. Cortes a flor de piel: una aproximación psicoanalítica a la conducta de la autoincisión en la adolescencia. Katahrsis 2014; 18:117-40.

20. Kamphuis J, Ruyling S, Reijntjes A. Testing the emotion regulation hypothesis among self-injuring females: Evidence for differences across mood states. J NerMent Dis 2007; 195(11):912-8.

21. Gaete V. Desarrollo psicosocial del adolescente. Rev ChilPediatr 2015; 86(6):436-43.

22. Miranda D. The role of music in adolescent development: much more than the same old song. Int J Adolesc Youth 2013; 18(1):5-22.

23. Moreno M, Ton A, Selkie E, et al. Secret Society 123: understanding the language of self-harm on Instagram. J Adolesc Health 2016; 58(1):78-84.

24. Lewis S, Mahdy J, Michal N, et al. Googling self-injury. The state of health information obtained through online searches for self-injury. JAMA Pediatr2014; 168(5):443-9.

25. Selby E, Kranzler A, Fehling K, et al. Nonsuicidal selfinjury disorder: The path to diagnostic validity and final obstacles. ClinPsychol Rev 2015; 38:79-91. 


\section{Annex 1.}

Physical habit of adolescents with self-injuries during medical consultation: pronated forearm
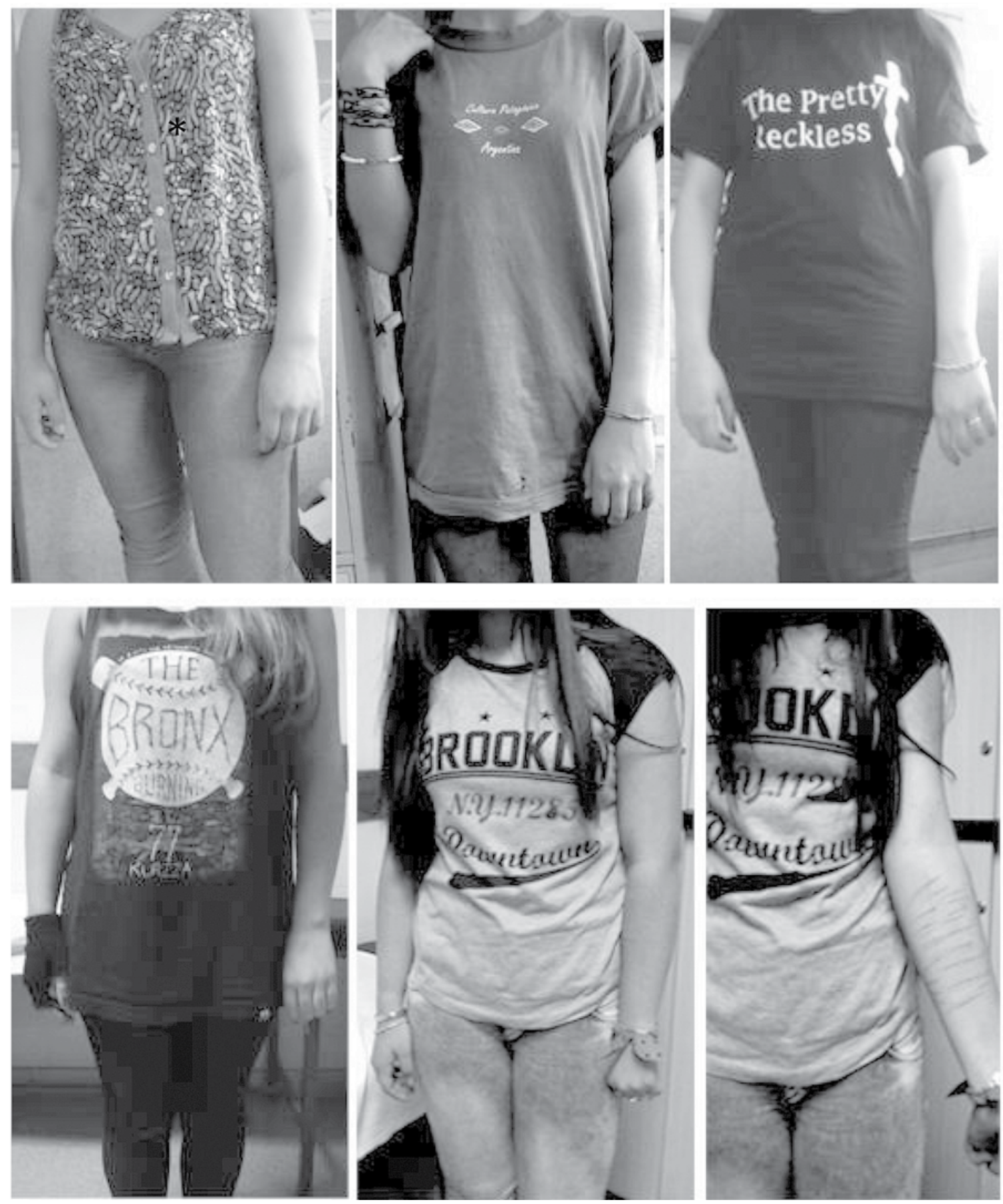


\section{Annex 2. \\ Accounts of adolescents with self-injurious behaviors: context, premeditation, and conflict with the adult world*}

Dahiana (16): "I started cutting myself and was frightened at first because it hurt, so I did small cuts and stopped. Then, with time, I started cutting harder and deeper because... I was angry [...]. After cutting myself, the next day I felt OK, it was an outlet, and I did it until my arm got used to it, I don't know, it didn't hurt anymore".

María (20): "It was on the spur of the moment. If you think too much about it, you don't cut yourself. That's the problem, while you cut yourself, you don't think much or little, you don't think at all! So you do it, because if you thought about it, you wouldn't do it".

Fany (17): "I knew I always kept a piece of glass, always. Even when I regret and say 'That's it, I'll throw it all away, no, I'll keep this one.' I always kept a piece because I knew I'd do it again".

Sofía (13): “[...] those who don't cut themselves say: 'Don't do it, it's pointless,, 'It's your skin, silly, take care of it,' and I say: 'So what? It's going to grow again. It's only a thing of the moment, I won't do it for the rest of my life,' I say. And they say: 'Still, don't do it' but I don't listen to them. And I do it."

Natasha (16): "[...] it's always for the same reason, when I argue with my mom. For example, the other time, I skipped school and... my mom and I started talking, arguing and she said a lot of things and I just got angry and then... I mean, I felt bad for what I had done, I was sad and... I don't know, I cut myself. It's like a habit now, every time I feel angry or sad, I cut myself. It's like taking it out on me by hurting myself."

Nahir (13): "It was a common thing, arguing with her (her mother), really, really common, but I didn't always cut myself. I did it when she said something that hurt, like saying that I was a bad daughter. It pissed me off, so I would cut myself, for example... OK, you've hurt me, I'll hurt myself even more. When I did it, I felt better, I felt free. I cut myself and felt all my problems went away, but I didn't realize there were more coming."

Sol (14): "Yes, I was doing the dishes and my mom saw me. But she saw me and said nothing. I mean, I realized she saw me but she didn't say anything, she didn't bring it up. I would have expected her to worry or something. Anyway, I didn't want her to ask questions because it's awkward talking about it."

Juliette (16): “They would only say: 'Don't do it,' that's all, it's not like they're worried and all. 'Don't do it, you're messing with yourself, you don't hurt me, only yourself.' That's what my parents say."

Mariana (14): "We were four friends and one of them had a boyfriend and she was all messed up and started cutting herself so we did it with her. We started there, at the school restroom, using a piece of broken mirror. [...] It was on the spur of the moment. She said: 'This is our secret,' so we did it to avoid getting in trouble, but then she showed it to everyone. [...] The principal asked us to tell him how we did it and why, then we got out and he talked to her alone. [...] That's when she started crying and told him about her mom, that she had a tumor in her head [...] and that her dad uses drugs and hits her and her mother. So she didn't just cut herself because of her boyfriend, she did it because of what was happening at home... that's why."

Jazmín (16): “[...] I can't talk much with my mom, I only tell her about how my day was, nothing else. [...] Because she's not the same as before. Because when someone hurt me or something, she would say: 'Don't worry, it's going to be OK,' she used to say. Now... now she just says: 'Suck it, see? I told you.' She won't hug me or show me affection like she did when I got hurt. It's like now my mom's grown apart from me. I can only count on my godmother, but now... she doesn't talk to me like she used to. She doesn't even remember me."

Leyla (14): “Sometimes you have problems with your dad because he's a player [...] and your mom's sad, so you see your mom feels bad and there's nothing you can do. I mean, it's their problem, but still, you don't like seeing your mom upset because of your dad, and when they get home, they don't talk to each other and all that stuff. Sometimes you feel bad and you can't talk about it with anyone because the people you're supposed to talk to, your mom and your dad, they are the cause of the problem." 
María (20): - A part of me wanted them to find out, to tell them, to get it all out, the bandage on my hand, but no. I didn't want them to find out, so no, they didn't. [...] I put a bandage on my hand, I remember it was a blue bandage, because I couldn't wear a white one, and I used long sleeves; it wasn't cold but I was wearing a long-sleeve shirt. I had to hide it so that they wouldn't notice what I had done. The next day it was all OK, as if I hadn't cut myself.

-What did you do so that they wouldn't find out?

-I wore long sleeves, I didn't spend much time with my family, I didn't hug my mom or my siblings, I didn't play fight with them or do the dishes because I didn't want, I didn't want them to find out. I had to be careful with those things so that they wouldn't see the cuts in my arm.

Francisco (17): "I had never thought about hurting myself, but it happened one time I felt bad and I said... well, because I had been helping anotherperson who also did it. And I felt bad because of this person because she had also hurt me and I felt alone, I wasn't on good terms with my family. So at one time I said: 'If everyone's hurting me, why don't I do it myself?'."'

* Interviewees are presented under a false name and their age is indicated between brackets. 


\section{Annex 3. \\ Accounts of adolescents with self-injurious behaviors: being "suicidal," circulation of cuts among peers, and social networks*}

Nicole (14): "One day we were talking about it, they mentioned they cut themselves, all that, that now everyone's doing it and I asked one of the boys: 'Do you do it?', and he said: 'Yes,' and pulled up his sleeve and he was all cut like this, with the pencil sharpener. The other guy said he also did it, but on his legs so that no one would see the cuts."

María (20): "If I had fulfilled my goals I would have stopped cutting myself or, actually, I wouldn't have been so angry like I was. I didn't fulfill my goals, and I couldn't comply with this thing of wanting to die either. Because when you want to die, you want to die, not that you want to kill yourself. That's very different. You want to die because you're tired of being yourself, of having so much weight on your shoulders. When you say you want to die, it means that, you don't want to kill yourself. Those are two different things [...]. No, I didn't mean to kill myself [...]; pain sets like a limit to making deeper cuts."

Araceli (14): "Some just want to say: 'Oh look, I cut myself' or want someone to worry about them. Some girls cut themselves because they like a boy and he won't pay attention to them or even talk to them, he doesn't want anything to do with them so they cut themselves so that he would talk to them or pity them. Others do it because they have too many problems and cannot take it anymore so they cut themselves. And other girls have the same problem I have. But many girls cut themselves just to do it, not because they have a problem."

Gonzalo (16): "Most kids who cut themselves want to be called 'suicides' because most do it for love, or sometimes they want to take pills because... they suffer all day or have family problems. [...] Because they understand one another, they understand the pain, the scars, everything, why they did it, why they suffer. Most will say they want to kill themselves, but they don't have the courage to do it, I mean... they think about killing themselves but they don't have the pills, they don't want to cut their veins or something like that. Maybe that's why they call themselves 'suicides'."

Macarena (13): "Once a friend told me she did it because she had problems with her mom and asked if I wanted to give it a try and I refused, but then, one day I was feeling bad and I tried. Then I didn't feel good doing it and I stopped. For a time, it kind of made me calm down but then it made me feel worse."

Nahir (13): "I had an Instagram account for suicidal or self-injuring girls and I had many followers, I would post pictures of my cuts, pictures and phrases. They would leave comments and liked my picture. Yes, because they would all tell me not to do it, asked why I did it; that I could count on them, too: 'You can talk to me in private,' 'You can tell me what's wrong' [...]. Even though I didn't know them, they... they... kind of cared about me. And many people talked to me, that was weird. They all talked to me."

Julieta (15): "I've been watching music videos and, well, some were kind of... sad songs. A girl published about a WhatsApp group for self-injuring people and I became a member. And well, I met people who do the same thing as me. We sort of help one another. When we were about to do it, we would tell the others and well, many of them helped you and prevented you from doing it."

Ana (16): "I found many pages for people like this using Facebook [...]. They posted phrases and pictures that I liked, I identified myself with them, but I wasn't looking for anything in particular. But I felt that at least someone understood me. For a moment there was... I don't know the word for it but several people with this problem did this thing of drawing different color hearts on the scars, each color meant something, and I did it, took a picture, and posted it. And my pictures were there online. They published them in several Facebook pages and I was surfing the sites and saw my pictures and those of other people."

Sofía (14): "I was talking to an ex... and I had hurt him, supposedly, he said he had suffered too much since we broke up. And I was really upset so I wrote 'I'M SORRY'; you can't see it because I used healing ointment... but I took a picture and sent it to him. I told him: 'I'm sorry for everything, for the pain I caused you, now I know how you felt all this time.' [...] And he laughed and said: 'Ha, ha, ha, I have no idea what you're doing but that's not my problem and I have nothing to do with that', he wrote. So I got really sad. It was the first time I shared a picture, to show him how bad I felt and that... that... that I was sorry for hurting him." 
Lucía (19): “I remember I was sitting next to a classmate and she asked: 'What's that?'; 'Nothing', and she did this (pulled up my sleeve) and saw the cuts and slapped me in the arm: 'This better be the last time I see you're cutting yourself.' [...] Then she started doing it and I wanted to kill her [...]; she started with a pin and then she started cutting herself with... she took the blade of a pencil sharpener and used that. And once I said: 'Even if I do it, you don't have to do everything I do.'.'

Agostina (19): “[...] I don't regret what I did, because I did it for a reason, I'm not ashamed or anything, I go around with my scars. Besides, I'm not the only one, in the bus, you see a girl sitting with a boy with their arms like this and when they move their hands, you see the scars. Everyone has them. Now it's like... when I used to do it there were few of us and we had a reason to do it, now everyone's doing it because it's a fashion [...]. It makes no sense anymore."

${ }^{*}$ Interviewees are presented under a false name and their age is indicated between brackets. 